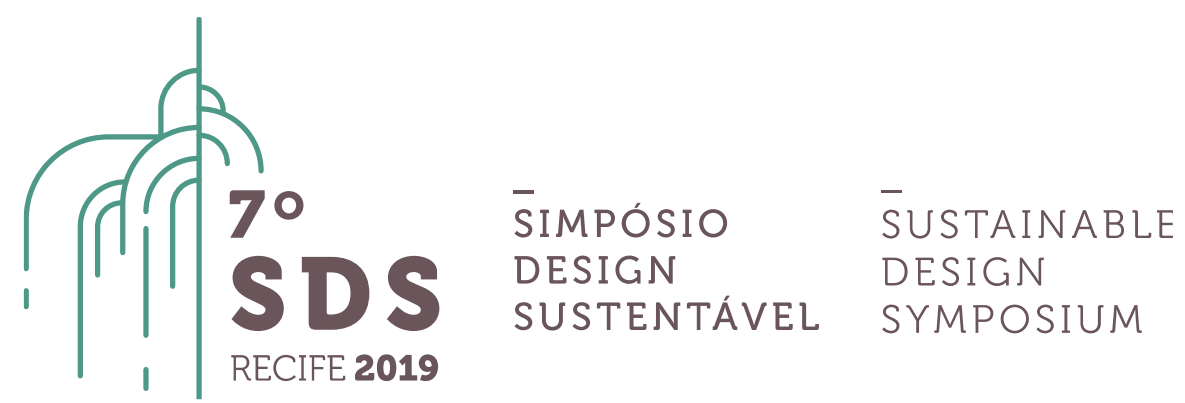

\title{
A Sustentabilidade Social e Econômica nos Processos de Reciclagem de Papel do NEAM/PUC-Rio
}

\author{
Davison Coutinho', Marina Moreira², e Fernando Matos ${ }^{3}$ \\ ${ }^{1}$ Doutorando em Design, PUC-Rio, Departamento de Artes e Design, Email: davisoneam@puc-rio.br \\ ${ }^{2}$ Doutora em Design, PUC-Rio, Núcleo de Estudo e Ação Sobre o Menor, Email: marinamoreira@hotmail.com \\ ${ }^{3}$ Técnico em Reciclagem, PUC-Rio, Núcleo de Estudo e Ação Sobre o Menor, Email: nandomatos40@gmail.com
}

\begin{abstract}
Resumo. $O$ presente artigo tem como objeto de estudo os processos de reciclagem de papel desenvolvidos por meio de oficinas práticas e participativas, junto a jovens de comunidades de baixa-renda, constituintes do Núcleo de Estudo e Ação Sobre o Menor da PUC-Rio. O papel reciclado serve como matéria prima à fabricação de produtos artesanais. Para tal, utilizam-se a observação sistemática, a análise dos processos de fabricação e a entrevista com seus autores. No seguimento, constata-se que o aprendizado dos jovens, por meio dessa prática, habilita sua consciência para a necessidade da preservação dos recursos naturais e humanos do planeta e da consequente promoção da sustentabilidade, enquanto aprimora a autoconfiança e desperta suas potencialidades.
\end{abstract}

Palavras-chave: Reciclagem; Sustentabilidade; Jovens; Inovação Social.

\section{Introdução}

O termo Sustentabilidade foi utilizado oficialmente pela primeira vez na Assembleia Geral das Nações Unidas, em 1979 (Boff, 2002). Na última década, com maior intensidade, percebe-se cada vez mais a citação, discussão e emprego desse conceito em pesquisas nos mais diferentes campos. A sustentabilidade é uma preocupação do NEAM/PUC-Rio, desde 1994, quando foi criada a máquina Milênia de reciclagem de papel. Passados mais de 25 anos de sua criação, o Núcleo continua a investir em uma formação interdisciplinar, educando jovens conscientes de suas responsabilidades sociais enquanto cidadãos.

A criação da Milênia teve como objetivo principal o desenvolvimento de uma pedagogia da transformação, em que se constrói a consciência ambiental do jovem que aprende a reciclagem por meio de um fazer com prazer, que motiva, inspira e cria novas perspectivas de conhecimento. Portanto, este artigo objetiva compreender e relacionar os processos técnicos de reciclagem desenvolvidos na oficina, por jovens de comunidades de baixa-renda, essência do NEAM, a uma 
contínua descoberta do processo individual do "Fazer" e do impacto dessa atividade na sua formação.

O Design é o caminho escolhido para esta investigação, uma vez que a relação do NEAM/PUCRio com esse campo é histórica. Ao longo dos 38 anos de sua existência, diferentes projetos foram realizados com alunos e professores do Departamento de Artes e Design da PUC-Rio (DAD), por meio da abordagem do Design Social, iniciada na universidade pelos pesquisadores José Luiz Mendes Ripper e Ana Branco. O redesenho da máquina Milênia foi objeto de trabalho de conclusão de curso em Design da aluna Maria Luiza Albuquerque, com orientação de Gustavo Bonfim e Sidnei Freitas, em 1999. Essa influência nas ações do núcleo é comprovada por jovens que, a partir da formação no NEAM, ingressaram na trajetória acadêmica em Design.

\section{O Núcleo de Estudo e Ação Sobre o Menor: Conexão com a máquina Milênia de Reciclagem de Papel}

O Núcleo de Estudo e Ação Sobre o Menor (NEAM/PUC-Rio) é uma Unidade Complementar da PUC-Rio, vinculada à Vice-Reitoria para Assuntos Comunitários, constituindo uma plataforma para a inclusão social de jovens e adolescentes, oferecendo diferentes atividades interdisciplinares de extensão comunitária. Com 37 anos de conquistas, colaborando com a sustentabilidade humana, inspira-se na solidariedade e na fraternidade cristã, procurando redirecionar a expectativa de vida dos adolescentes de segmentos sociais de baixa renda, a fim de que sejam cidadãos e agentes multiplicadores da transformação nas sociedades em que vivem. Ao longo de sua história, o NEAM especializa-se em enfrentar o problema da educação enquanto processo, associando o Saber ao Fazer.

Transportando o conhecimento do pesquisador para o fazer da formação do jovem técnico, a Máquina Milênia de Reciclagem de Papel foi idealizada pelo professor José Eugênio Leal, de Engenharia Industrial da PUC-Rio, em 1999 (Moreira, 2006). Na perspectiva de uma pedagogia da transformação, tem como ponto de partida a conscientização sobre as necessidades para a sobrevivência e sustentabilidade do planeta, enquanto estimula o desenvolvimento da autoconfiança e as potencialidades humanas dos alunos, conforme afirma Leal (1996):

O surgimento da Milênia nos permitiu criar uma pedagogia da transformação. O aprendiz do reciclado participa de um processo de conhecimento e organização, que o motiva a produzir e criar num fazer com prazer. Mais lucro do que isso é só a certeza de uma parceria que transforma o pesquisador à formação de jovens, numa relação harmônica entre conhecimento e realização. (LEAL, 1999)

O uso da tecnologia apropriada à produção do papel reciclado tem duplo impacto social. De um lado, entrega nas mãos dos jovens a possibilidade de aprender na prática como solucionar problemas, reaproveitando matéria prima e transformando-a em um objeto necessário a sua demanda. De outro lado, incorpora ao processo produtivo essa mão de obra, capacitando e conduzindo-a a assumir novas tarefas em setores mais modernos da economia. 
Figura1: Primeira versão da máquina Milênia, 1999; Figura 2: versão atual da máquina Milênia

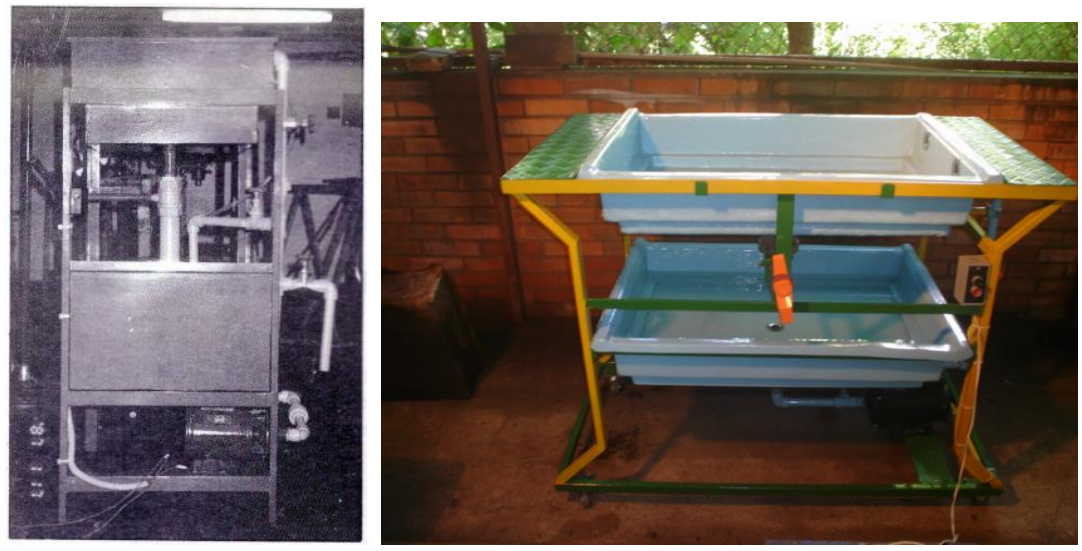

Fonte: acervo NEAM/PUC-Rio; Fonte: Elaborado pelos autores

\section{A sustentabilidade: uma premissa para o Design de Inovação Social}

O conceito de sustentabilidade tem sido amplamente utilizado por autores, empresas e governos. Para Boff (2012), sustentabilidade significa a realização de ações que visem cuidar da Terra preocupando-se não apenas com a população atual, mas também com as futuras gerações. Tais ações, infelizmente, ainda não são comuns por parte das empresas, e muitas delas, segundo o autor, existem para ludibriar o consumidor, vendendo produtos que ele nomeia de greenwash, ou seja, pintado de verde, mas que seus meios de produção agridem o meio-ambiente. $O$ autor afirma que uma sociedade sustentável é aquela que se organiza garantindo a vida dos cidadãos e dos ecossistemas. Nesse sentido, Mazini também aponta o que seria caminhar para uma sociedade sustentável:

Caminhar rumo à sustentabilidade é ir na contramão do conservadorismo, em outras palavras, preservar e buscar a regeneração do nosso capital ambiental e social significa romper com as tendências dominantes em termos de estilo de vida, produção e consumo, abrindo-se para novas possibilidades. (MANZINI, 2008 p.15)

A preocupação de Boff e Manzini alerta-nos sobre os limites dos recursos de nosso planeta e sobre se fazer necessário um desenvolvimento sustentável que possa beneficiar a todos e todas, inclusive às próximas gerações. Uma sociedade sustentável, para os autores, não engloba apenas questões ambientais, mas também sociais como a superação da pobreza, a geração de empregos dignos, a igualdade social e a redução da desigualdade econômica.

\subsection{Design e Sustentabilidade}

Antes mesmo de se tornar um termo amplamente difundido, a sustentabilidade era uma grande preocupação de Papanek (2005), um dos pioneiros do Design Sustentável. Em 1971, ele já alertava sobre os impactos da produção de bens e produtos que desperdiçavam recursos naturais e agrediam o meio ambiente. O autor também questionava o papel e a responsabilidade social dos designers. Desde então, segundo Margolin e Margolin (2004), muitos designers têm procurado desenvolver modelos sustentáveis de práticas para necessidades sociais, incluindo soluções para os problemas de países em desenvolvimento, populações de baixa-renda e pessoas com deficiência ou portadoras de necessidades especiais em decorrência da idade. 
Nessa perspectiva, a sustentabilidade é uma das premissas do Design Social, que busca desenvolver soluções para a melhoria da qualidade de vida das pessoas e do meio ambiente, projetando modelos sustentáveis e não assistencialistas:

“[...] designer e a sua capacidade de imaginar e dar forma em produtos materiais e imateriais que podem resolver os problemas humanos em larga escala e contribuir para o bem-estar social" (MARGOLIN, 2004).

Corroborando com a afirmação de Margolin, Bonsiepe (2011) apresenta-se o conceito de Humanismo Projetual, também com objetivo de compreender às necessidades de grupos sociais e desenvolver propostas autônomas, focando também nos menos favorecidos economicamente:

\begin{abstract}
O humanismo projetual seria o exercício das capacidades projetuais para interpretar as necessidades de grupos sociais e elaborar propostas viáveis, emancipatórias, em forma de artefatos instrumentais e artefatos semióticos. Por que emancipatórias? Porque humanismo implica a redução da dominação e, no caso do design, atenção também aos excluídos, aos discriminados [...] (BONSIEPE, 2011, p.21).
\end{abstract}

\title{
3.2. Design e Inovação social
}

As pesquisas de diferentes autores sobre Design Social, preocupados com as questões sociais e ambientais, contribuíram para que a inovação social fosse considerada no Design (CIPOLLA, 2007), o que Manzini define como Design para Inovação Social.

Segundo Manzini (2008), a inovação social se refere a mudanças no modo como os indivíduos agem para resolver seus problemas. O autor propõe iniciativas de trabalho colaborativo, formada por grupo de voluntários, na busca de soluções de problemas de suas comunidades e que contemplem a descontinuidade dos padrões formais de produção e consumo. O que ele intitula de Comunidades criativas.

Segundo Joly (2015), o designer pode atuar de duas formas em iniciativas de design para inovação social, trabalhando com ou para a comunidade:

1. Com a comunidade: o designer atua como parceiro da ação, em uma pesquisa-ação.

2. Para a comunidade: o designer analisa iniciativas existentes e identifica intervenções por ele dominadas e com as quais possa contribuir.

Nesse sentido, busca-se, por meio dessa relação dos pesquisadores com os jovens do NEAM, no fazer artesanal do papel reciclado, a melhoria da qualidade de vida dos participantes e a extensão dessa atividade a outros campos. Essa inteiração com a comunidade, de troca de saberes acadêmicos e populares, na busca de soluções de problemas (comunidades criativas), respalda o Design para Inovação Social.

Por meio do Design para Inovação Social, propõe-se que este estudo fomente a implementação de outras oficinas, tornando esta metodologia uma tecnologia social. Nessa perspectiva, estimular essa iniciativa local de produção de papel reciclado, cria rupturas nos padrões de consumo e formas de produção, contribuindo para a sustentabilidade e empoderamento das pessoas.

\subsection{A sustentabilidade do NEAM na reciclagem de papel}

No que tange à sustentabilidade social, o NEAM tem se empenhado no desenvolvimento de jovens de maneira contagiante, levando essa preocupação ao meio acadêmico de forma exemplar e participativa. O conjunto de ações educacionais torna-se importante para que o crescimento dos jovens seja uma vertente de ordem estratégica do Núcleo na busca de melhores caminhos para a integração socioeducativa.

Transversalmente ao cotidiano da oficina de reciclagem de papel, há a chancela da interceção entre os três fatores da sustentabilidade: social, ambiental e econômico. A oficina possibilita o 
desenvolvimento a partir de ações práticas em um contexto real, no qual o estímulo se dá ao jovem como parte importante desse conjunto de medidas. Essas medidas são transformadas por intermédio da fabricação de papel, sobretudo, na materialização de produtos reciclados. Essas ações possibilitam aos jovens terem uma visão macro de soluções a problemas em seus bairros, assim, ainda que sejam eventos específicos, eles se tornam sujeitos referenciais e multiplicadores, intervindo naquele ambiente, modificando aquela cultura.

O potencial para a geração de renda na oficina é evidenciado. No entanto, não é o objetivo da repetição alienante de processos e movimentos, visando à obtenção de dinheiro. A geração de renda é um aspecto importante, mas não pode se contrapor ao desenvolvimento humano. $\mathrm{Na}$ questão econômica, o NEAM, a partir da implementação da oficina de reciclagem, proporciona aos jovens uma conscientização econômica, devido às implicações produtivas.

Quando o NEAM faz a reciclagem ou o reaproveitamento de matéria prima, põe em prática a economia criativa que tem se popularizado. Os pilares de formação de modelo baseiam-se na economia de uso, na economia de funcionalidade e na economia de desempenho, premissas do Design Sustentável.

\section{4. $O$ processo de trabalho da oficina Milênia}

Figura 03: Produção da Polpa ; Figura 04: Moldagem da folha ; Figura 05: Secagem
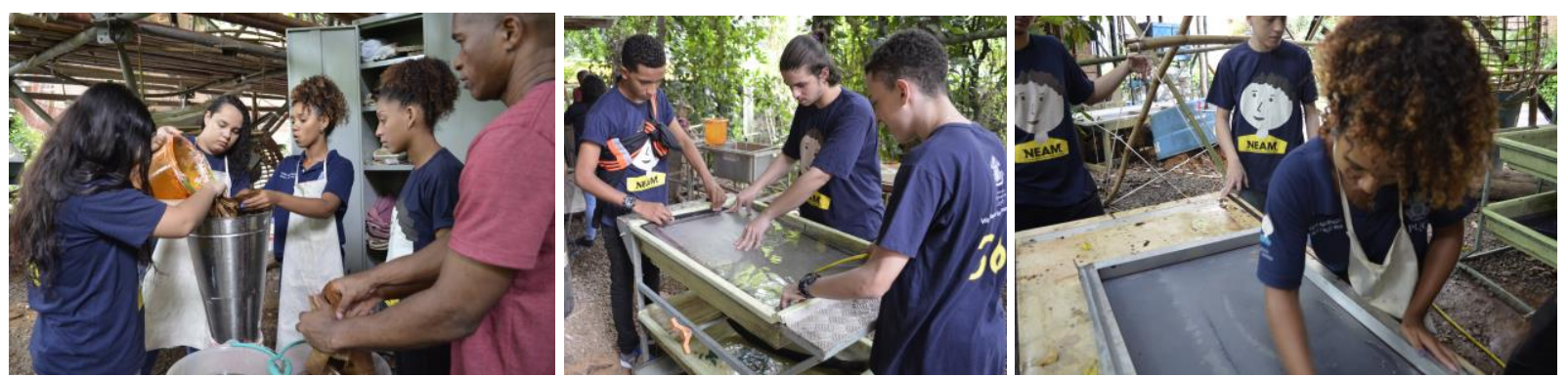

Fonte : Elaborado pelos autores

Um dos objetivos deste estudo é o de analisar as etapas e definir em um diagrama para facilitar a explicação, o ensino dos jovens e também a possibilidade de reaplicação da oficina em outras instituições, o que é uma proposta antiga do Núcleo.

A integração dos alunos na oficina representa uma forma de interagir os conhecimentos e culturas dos jovens, cada um traz uma proposta diferente e é agregada à proposta do NEAM como matriz. Os primeiros passos dentro da oficina ensinam aos jovens sobre funcionamento e processamento do papel. Então, dá-se início aos processos de fabricação que partem da preparação da máquina, do liquidificador, da tela de moldagem e da seleção de papéis.

O envolvimento dos jovens nos processos começa dentro do NEAM, onde usam e descartam o papel de forma consciente. A seleção dos papéis acontece dentro do Núcleo, onde participantes utilizam papel A4, jornais, revistas e papelão. Assim, começam a entender que o processo de reciclagem representa, primeiramente, a redução do uso, além das etapas de separação por cores e gramatura para a fabricação de uma folha de qualidade.

Após a classificação, o papel é levado para umidificação, fica de molho (estado de decomposição) por um dia e, após essa etapa, está preparado para o processo de trituração. Nessa parte do processo, acontece a coloração que faz uso de corantes naturais e artificiais. Além das cores do próprio papel descartado. Nessa mistura, inclui-se a cola de celulose que possibilita resistência e flexibilidade à folha. Originasse, assim, a polpa, matéria prima para a produção do papel. 
Após o preparo da máquina Milênia, inicia-se a etapa da moldagem da folha em uma tela de alumínio e nylon, na qual se despeja a polpa criada na etapa anterior.

$\mathrm{Na}$ etapa final, acontece a sedimentação (secagem), na qual sucedem as transformações e a maturação após dois dias. Por fim, ocorre a descolagem das folhas.

Todos os alunos do Núcleo aprendem a fabricar o papel reciclado e, a partir dessa aprendizagem, utilizam o papel para produzir diversos objetos. Os jovens entendem o processo de fabricação, descobrindo que o papel usado transformou-se em uma folha com características exclusivas que pode ter diferentes usos: cadernos, caixas, bolsas e outros produtos.

Nessa experiência de experimentação, os jovens adquirem autoconfiança e suas habilidades nas lides do fazer. Por conseguinte, sua capacidade é instigada e, ao mesmo tempo, aprendem que errar faz parte da construção do conhecimento.

Figura 6: Fluxograma do Processo de reciclagem de Papel.

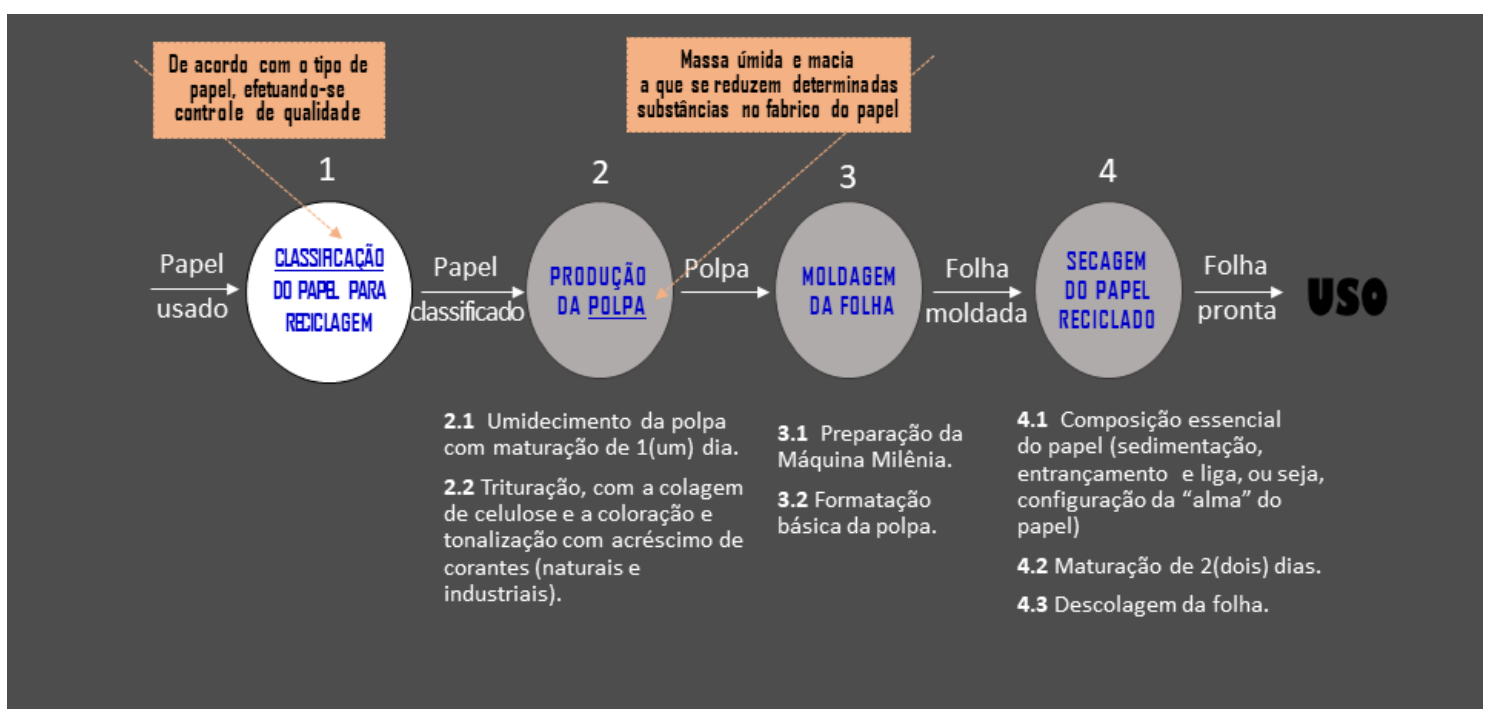

Fonte: elaborado pelos autores com base na pesquisa

\section{As entrevistas com os participantes e suas análises}

Foram realizadas entrevistas estruturadas com sete jovens entre 15 e 18 anos. Utilizamos os seguintes critérios para a seleção dos jovens a formarem o grupo entrevistado: atuação individual em mais de três vezes na experiência de reciclagem de papel; possuirem diferentes períodos de participação no Núcleo, categorizando-os em dois níveis, jovens iniciantes (até 1 ano de participação no NEAM) e jovens experientes (acima de 1 ano de participação no NEAM); serem oriundos de diferentes comunidades e estarem em diferentes níveis de escolaridade.

Foram elaboradas três questões, além da coleta de informações pessoais. O objetivo foi de compreender como a prática de reciclagem de papel impacta na vida dos participantes e como eles entendem as etapas do processo de reciclagem. As entrevistas foram realizadas individualmente no NEAM e em sala de aula. A seguir, apresentam-se os perfis dos entrevistados, os resultados e a análise das entrevistas.

\subsection{Perfis dos entrevistados}

Tabela 1: Perfis dos jovens entrevistados

\begin{tabular}{|l|l|l|l|l|}
\hline Jovem & Idade & Bairro & Escolaridade & Período de participação \\
\hline
\end{tabular}




\begin{tabular}{|ll|l|l|l|l|}
\hline & & & & & no NEAM \\
\hline 1. & Gabriel & 17 & $\begin{array}{l}\text { Comunidade Vila Parque da } \\
\text { Cidade }\end{array}$ & Ensino médio completo & 2 anos (experiente) \\
\hline 2. & Gabrielly & 17 & Comunidade da Rocinha & 20 ano do Ensino médio & 3 anos (experiente) \\
\hline 3. $\quad$ João & 18 & $\begin{array}{l}\text { Comunidade Vila Parque da } \\
\text { Cidade }\end{array}$ & 2 o ano do Ensino médio & 5 anos (experiente) \\
\hline 4. & Laura & 18 & Ladeira dos Tabajaras & Ensino médio completo & 3 anos (experiente) \\
\hline 5. & Leonardo & 15 & Botafogo & 10 ano do Ensino médio & 6 meses (iniciante) \\
\hline 6. & $\begin{array}{l}\text { Maria } \\
\text { Eduarda }\end{array}$ & 15 & Comunidade da Rocinha & 10 ano do Ensino médio & 6 meses (iniciante) \\
\hline 7. & Mariane & 16 & Comunidade da Rocinha & 20 ano do Ensino médio & 6 meses (iniciante) \\
\hline
\end{tabular}

Fonte: Elaborado pelos autores.

\subsection{Apresentação e análise dos resultados}

A análise dos resultados das entrevistas foi feita utilizando o método de análise de conteúdo. Para tal, foram realizadas as seguintes etapas: a) leitura flutuante do material; b) exploração do material das entrevistas; c) elaboração de categorias de análise e d) identificação das categorias nas entrevistas.

Estabeleceram-se as seguintes categorias: Conscientização da sustentabilidade; Percepção de aprendizado; Compreensão das etapas da reciclagem e Identificação das etapas de maior interesse;

\subsection{Resultados da análise de conteúdo}

A partir das categorias identificadas, examinou-se o material das entrevistas a fim de identificar em quais entrevistas estes estão presentes ou ausentes. Os candidatos estão representados por números correspondentes à tabela 1. Os dados se apresentaram da seguinte forma:

Tabela 2: Resultados da entrevista

\begin{tabular}{|c|c|c|c|c|c|c|c|c|c|c|c|c|c|c|}
\hline \multirow[t]{2}{*}{ Entrevistado } & \multicolumn{2}{|c|}{1} & \multicolumn{2}{|c|}{2} & \multicolumn{2}{|l|}{3} & \multicolumn{2}{|c|}{4} & \multicolumn{2}{|c|}{5} & \multicolumn{2}{|c|}{6} & \multicolumn{2}{|c|}{7} \\
\hline & $A$ & $\mathrm{P}$ & A & $\mathrm{P}$ & A & $\mathrm{P}$ & $A$ & $P$ & A & $\mathrm{P}$ & $A$ & $\mathrm{P}$ & $A$ & $P$ \\
\hline Conscientização da sustentabilidade ambiental & & $\mathrm{x}$ & & & & $\mathrm{x}$ & & & & $\mathrm{x}$ & & & & $\mathrm{x}$ \\
\hline Percepção de aprendizado & $\mathrm{x}$ & & $x$ & & $\mathrm{x}$ & & & & & & & & & \\
\hline Compreensão das etapas da reciclagem & & & $\mathrm{x}$ & & & & & & & & $\mathrm{x}$ & & & \\
\hline Identificação das etapas de maior interesse & $\mathrm{x}$ & & $\mathrm{x}$ & & $\mathrm{x}$ & & & & & & $\mathrm{x}$ & & $\mathrm{x}$ & \\
\hline
\end{tabular}

Fonte: Elaborado pelos autores

Legenda: A - ausência; P-presença

Em relação aos discursos dos entrevistados 1, 3, 5, 6 e 7 pode-se identificar a presença da categoria Conscientização da sustentabilidade ambiental. Todos esses jovens afirmaram em suas entrevistas a relevância de reciclagem de papel como uma solução para minimizar os impactos gerados no meio ambiente. Essas ideias são expressas, evidentemente, quando os jovens dizem:

“(...)reaproveitar as coisas ao invés de jogarmos fora, sempre vai servir para algo. Como aqueles papéis que, ao invés de serem descartados, foram reaproveitados e utilizados para muitas coisas." (Gabriel) 
"Fazendo papel reciclado, aprendemos de forma divertida a nos conscientizar sobre a importância da reciclagem para o meio-ambiente." (João Eugênio)

"É uma forma de ajudar o meio ambiente de um jeito legal. Para muitas pessoas, pedaços e restos de papéis são lixos" (Laura).

"Poder reutilizar um objeto que iria poluir o mundo" (Leonardo).

"(...)podemos reciclar tudo e, com isso, aprendemos que não é bom jogar coisas fora" (Maria Eduarda).

Nessas respostas, cabe ressaltar as relações que foram feitas com o reaproveitamento de outros objetos que são geralmente descartados. O que demonstra que a ação de reciclar papel gera uma consciência de reaproveitamento que ultrapassa os limites do papel, alcançando os 3 R's da reciclagem.

A categoria de Percepção de aprendizado esteve presente no discurso dos entrevistados 1, 2 e 3. Estes afirmam que consideram a experiência de reciclagem de papel como um aprendizado. A afirmação fica evidente nos seguintes trechos:

“(...) aprendi que, na maioria das vezes, temos como reaproveitar as coisas" (Gabriel).

"Aprendi a fazer diversas coisas com o papel reciclado e é uma coisa que eu posso ir à frente, caminhar para o futuro" (Gabrielly).

“(...)aprendemos de forma divertida" (João).

A compreensão dos jovens de que, a partir da reciclagem de papel, desenvolve-se um aprendizado indica que, por mais que as ações aconteçam de forma prática, eles as compreendem como atividades de ensino-aprendizado. A metodologia lúdica na produção desse aprendizado é expressada na afirmação do jovem João Eugênio quando revela que aprender a reciclar papel "é uma forma divertida de se conscientizar sobre o cuidado com o meio ambiente".

A categoria Compreensão das etapas de reciclagem esteve presente no discurso das jovens entrevistadas 2 e 6 , quando contam sobre o processo de reciclar papel:

Primeiro cortamos os papéis (branco/papelão). Botamos dentro da batedeira (liquidificador) os papéis cortados com água, cola em pó e corante. Depois bata essa mistura até virar uma polpa. Segundo, botamos água na máquina de reciclagem. Em seguida, botamos a tela e, aos poucos, botamos a polpa em cima da tela. Retiramos a tela e botamos um pano em cima do papel e depois apertamos devagar em cima para escorrer a água. Por último, pegamos a tela e apoiamos em cima de uma mesa, pegamos um pano e começa a secar a tela até sair toda água. Em seguida, retiramos com delicadeza a tela do pano e botamos no varal para chegar até o papel reciclado. (Gabrielly)

"Eu rasguei os papéis, coloquei na máquina (liquidificador) que triturou tudo e, assim, colocamos a polpa numa tela sobre a água e depois retiramos, secamos a água e, por fim, colocamos para secar" (Maria Eduarda).

Enquanto Gabrielly e Maria Eduarda descreveram de forma completa o processo de reciclagem, parte dos entrevistados não responderam às etapas. Esse dado demonstra a utilidade do material desenvolvido que descreve as etapas, as quais serão utilizadas para a instrução dos jovens. 
Por isso, com base nas respostas das jovens Maria Eduarda e Gabrielly e na observação sistemática da oficina, foi desenvolvido o fluxograma das etapas do processo de produção do papel (figura 6). Este material, a partir de então, é utilizado pelo NEAM/PUC-Rio para o treinamento dos jovens.

Definidas as etapas de reciclagem, chegamos à categoria de Identificação das etapas de maior interesse por parte dos jovens. Para surpresa dos pesquisadores, três dos jovens entrevistados afirmaram que têm maior interesse na etapa de secagem, ou seja, finalização do processo. Quando eles conseguem visualizar o resultado de todas as etapas anteriores e conseguem retirar o papel seco e pronto para o uso:

"Secagem. Colocamos a tela com a polpa no pano, o jeito com que a polpa solta da tela e fica grudada certinha no pano" (João Eugênio).

"Secagem. Cada processo é extremamente importante, só que o processo de secagem me chamou mais atenção, porque você molda em um pano e deixa secar naturalmente e, depois de uns dias, estará pronto para reutilizar" (Laura).

"Secagem. Na etapa em que você passa o papel da placa (tela) para o pano, pois precisa ter bastante cuidado e ser delicado para o papel não desfazer" (Gabriel).

Duas outras jovens revelaram se interessar pelo preparo da polpa:

"Mistura da polpa. Me despertou maior interesse na etapa que mistura a polpa na água" (Maria Eduarda).

"Preparo da polpa. A parte em que o papel é triturado" (Mariane).

A jovem Gabrielly informou que tem maior interesse na etapa de moldagem da folha:

"Moldagem da folha. (A etapa) que eu mais me interessei foi a parte de montar. Botamos água na máquina de reciclagem e, em seguida, botamos a tela e, aos poucos, botamos a polpa em cima da tela".

O jovem Eduardo não soube responder por qual etapa tinha mais interesse. Acredita-se que esse fato tenha relação com seu pouco tempo de prática na oficina de reciclagem.

As entrevistas permitiram aos pesquisadores e também à coordenação pedagógica do NEAM/PUC-Rio conhecer e avaliar as práticas desenvolvidas na oficina de reciclagem de papel. Constatou-se que, de forma inconsciente, a prática estimula a consciência ambiental e a satisfação em reutilizar objetos. Foram aferidas as etapas com as quais os jovens têm maior entusiasmo de trabalho, por meio dos revezamentos, para que todos desempenhassem todas as etapas, e pela apuração ao se especializarem na que tinham maior interesse. Isso proporcionou a geração do fluxograma das etapas, que serve para a capacitação de outros participantes e como material essencial para a reaplicação da oficina em outros locais.

\section{Conclusão}

O Design, pela sua natureza diversa, foi fundamental para corroborar com a abordagem desejada, cooperando com seus saberes para possibilitar iniciativas essenciais para o melhor aproveitamento da matéria prima do papel na confecção de produtos. Esse fenômeno possibilitou a consolidação da relação do universo comunidade-universidade, construindo um conhecimento 
conjunto por pesquisadores e jovens, participantes do NEAM. Confirma-se, assim, a proposição de Papanek (2005), de que é possível levar o Design para atender projetos que contribuam com recursos para as populações menos favorecidas, por meio de soluções participativas.

O resultado evidenciado, tanto nas experiências de observação dos processos de reciclagem de papel na Oficina Milênia, quanto no conteúdo extraído das entrevistas, mostra que existe um potencial transformador nos jovens vinculados ao Núcleo. Concluímos que a sensibilização pelo processo do qual o jovem participa desperta sua consciência sobre as necessidades de sobrevivência dos bens do planeta e de sua sustentabilidade. Além disso, ensina aos jovens a prática do reaproveitamento de objetos, estimulando também a prática empreendedora.

Espera-se que os resultados desta pesquisa contribuam para a difusão da prática de reciclagem, por meio da reaplicação do processo em outros locais. Tem-se como intento a futura instalação em uma escola pública.

\section{Referências}

BONSIEPE, G. Design, cultura e sociedade. São Paulo: Blucher, 2011.

BOFF, Leonardo. Sustentabilidade, O que é - o que não é. Rio de Janeiro: Vozes, 2012

CIPOLLA, Carla. Design social ou design para a inovação social? Divergências, convergências e processos de transformação. In Ecovisões Projetuais: Pesquisas em Design e Sustentabilidade no Brasil, capítulo: 12. : Blucher Open Access, Editores: Alfredo Jefferson de Oliveira, Carlo Franzato, Chiara Del Gaudio, pp.147-154

JOLY, M. P. Design para a Inovação Social e a Rede DESIS no Brasil. Dissertação (Mestrado em Engenharia de Produção) - COPPE, UFRJ, Rio de Janeiro, 2015.

LEAL, José Eugênio. In: Publicação especial 15 anos do NEAM. NEAM: Rio de Janeiro,1996

MANZINI, Ezio. Design para a inovação social e sustentabilidade. Caderno do Grupo de Altos Estudos, COPPE/UFRJ. Rio de Janeiro: e-papers,2008.

MARGOLIN e MARGOLIN, Victor; Sylvia. Um "modelo social" de design: questões de prática e pesquisa. Revista Design em Foco, ano/vol. I. Universidade do Estado da Bahia, Salvador, 2004

MOREIRA, M. Universidade e Comunidade: a construção de um novo ambiente. Rio de Janeiro: epapers, 2006.

PAPANEK, Victor. Design for the real world. Chicago: Chicago Review Press, 2005. 